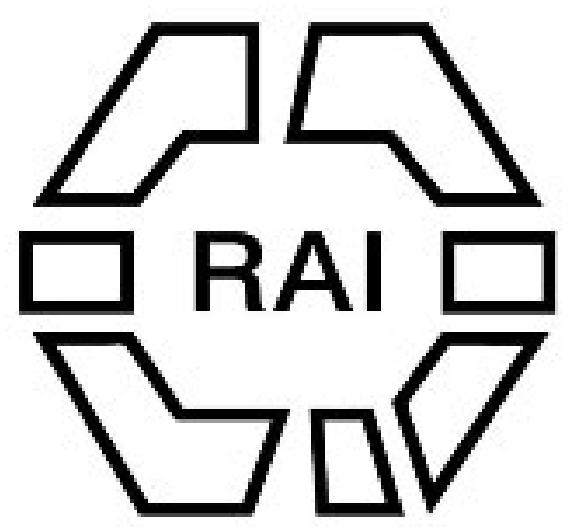

Nicobar Pottery

Author(s): E. H. Man

Source: The Tournal of the Anthropological Institute of Great Britain and Ireland, Vol. 23 (1894), pp. 21-27

Published by: Royal Anthropological Institute of Great Britain and Ireland

Stable URL: http://www.jstor.org/stable/2842311

Accessed: $15 / 06 / 2014$ 22:20

Your use of the JSTOR archive indicates your acceptance of the Terms \& Conditions of Use, available at http://www.jstor.org/page/info/about/policies/terms.jsp

JSTOR is a not-for-profit service that helps scholars, researchers, and students discover, use, and build upon a wide range of content in a trusted digital archive. We use information technology and tools to increase productivity and facilitate new forms of scholarship. For more information about JSTOR, please contact support@jstor.org. 
On the left is the "tambu house" with two old men sitting in front. Here are kept the "fish" and masks, "tambu hats," used in the dances.

Fig. 2.-A Group of so-called "Mummies."

These represent chiefs gone to the Shades and become "demits." They were brought on board at Port Sandwich, and were said to be from some inland village. The tall one on the left and the next largest have red skulls covered with sun-baked clay to make them look like faces. The body of the large one is made of bamboo frame, wattled and dabbed, and brightly coloured in red, black, and white. He holds in one hand a pig's jaw, and a "fish" in the other. The smallest of all is entirely clay, or rather mud, and twigs, and his head is founded on a cocoanut. The right hand one (with pigs' tusks) is a fern tree stump with a baked mud face, all brightly coloured.

The "fish" (so-called by the natives) is made of wood, and coloured; it is held in the hand while dancing, and was only placed in the mummy's to be photographed.

\section{Plate II.}

Fig. 1.-A "Demits" at Uripiv Island.

With the usual supporters with carved faces-made of fern tree stumps.

On the stone a crescent moon and a rainbow (?) in colours.

Fig. 2.-A "Demits" at Uripiv Island.

The stone is the "demits" and the attendant figures-a man on the left of the photo, a woman on the right, and (I fancy) an ambi-sexed creature in the centre are, as far as I could learn, accessories and supporters to the coral stone, which is the real object of worship.

\section{Nicobar PotTery.}

\section{By E. H. MaN, C.I.E.}

\section{[WITH PLATE III.]}

REGARDING the origin and manufacture of pottery by the Nicobarese, no traditions are seemingly extant, but a belief exists that in remote ages the Great Unknown, whom in later times they were taught by the missionaries to call Deuse, decreed that on pain of certain serious consequences-such as an earthquake or sudden death-the manufacture of pots was to be confined to the one small island of the group known to us as "Chowra," and that the entire work of preparing the clay and moulding and firing the pots was to devolve on the women of the community: it is further related that many years ago a Chowra woman while on a visit in one of the central islands thoughtlessly acted in contravention of the prohibition and attempted to make a cooking pot, but she forthwith paid the penalty of her 
disobedience with her life. This incident has consequently been held as confirmatory of the genuineness of the command and a warning against any rash trifling with the restrictions, which though imposed in far-off times, are yet of importance to be observed.

The clay employed in the manufacture-though perhaps the best available- $\rightarrow$ is not specially well adapted for the purpose, and moreover the monopoly during a long series of years having led to the exhaustion of the limited strata at Chowra, the requisite supplies of material have for many years past been obtained from a spot on the northern slopes of Teressa; as this necessitates a sea-trip of about five miles, the voyage is only undertaken in settled weather. The duty of procuring the clay and the sale of the finished article constitute the entire responsibility of the Chowra men in respect to the main industry of their island.

Indian pots ${ }^{1}$ and jars are purchased from traders who import them from Bombay, Penang, the Coromandel coast and Burma, and these, though stronger than those locally produced, are from their form-being provided with necks-unsuitable for steaming and boiling the Pandanus fruit, and are therefore reserved for cooking meat, fish, vegetables and rice which, however, might be equally well prepared in the home made utensil.

The Nicobarese pots are of six prescribed sizes, viz. :-

1: kentâha-lama-ok', measuring about 27-28 inches across."
1A : kentâha-lama-oall
"
$23-24$
,

1 The Indian pots are of four sizes and are made and used as follows:- (a) the largest (tòint) used for cooking rice, fish, pork, aud buffalo-beef; (b) a smaller size (kochì) used for boiling pork, dripping, and for mixing the Pandanus paste; (c) the third size (hulū) serves for boiling rice and jungle pork ; while (d) the fourth size (hidânh), is used indiscriminately for boiling vegetables, fish, fowls eggs, and pork of eitner kind. All these pots are purchased and kept on hand partly for general use and partly as a reserve stock in case they should run short of Chowra pots which they profess to prefer, though less durable, they however admit that they have some fear lest they should incur the resentment of the local manufacturers by patronizing exclusively the foreign article, and it seems more than probable that if the Indian pots were procurable in the same sizes and shape as those made at Chowra, the local trade would suffer considerable loss and eventually have to be abandoned.

2 From superstitious motives the use, or rather the purchase and ownership, of this large utensil is confined to the old members of the community some of whom use them when giving a feast. Young persons rarely if ever use a larger size than the han-shöi whatever the occasion may be, but they may eat food prepared by those whose age entitles them to the honour of cooking with a kentâha. The responsibility of deciding whether the proper age for possessing a kentâha has been attained is a personal matter, and though contrary to their ideas of the fitness of things, no one would prevent a young man from using a kentâha if he had the presumption to assume this prerogative of his seniors. As the kentâha is used throughout the archipelago by only a limited numbcr of persons, comparatively few specimens of this large size are produced, and care is taken to select the hottest season of the year as the most favourable time for their manufacture. 
2: han-shöi-lama-ok measuring about 18-19 inches across.

2A: han-shöi-lama-oal " " 16-17 " "

3: itâsha-lama-ok " " " $15-16 \quad "$

3A: itâsha-lama-oal " " " $13-14$ " "

4: henpak-ngaich-lama-ok " " 13-14 " "

4A: henpak-ngaich-lama-oal " $11-12$ " "

5 : panòkenlait-lama-ok " " $\quad 11-12 \quad " \quad$ "

5A: pandkenlait-lama-oal " " $\quad 9-10$ " "

$6:$ tafâl. Five different sizes measuring from 3-4 inches across the mouth which are used for boiling water and eggs only.

The largest of these pots is used only on feast days and for boiling pork. Sizes 2, 2A, 3, 3A are used for boiling pork, pandanus, and cycas paste, on ordinary occasions, while Nos, 4 , $4 \mathrm{~A}, 5,5 \mathrm{~A}$, are kept for boiling fowls, rice, vegetables and for making cocoanut oil; it will thus be seen that these utensils are not employed for cooking fish, which is prepared exclusively in Indian pots. ${ }^{1}$

As will be inferred from the measurements just given the pots are made in pairs of unequal dimensions so that they may be fitted one inside the other, and it should be mentioned that each pot has moreover a fixed market value.

With the exception of the tafâl, the various sizes are made with the lips curving more or less slightly inwards; they may be described as of an oblate-spheroidal form, and in the four medium sizes it is not uncommon for the larger size of one variety to correspond approximately in capacity with the smaller size of the next larger description. The reason for this want of uniformity will be understood when the crude method of manufacture has been explained, and it will be reaaily seen that though not intentionally so made, or arranged, it is quite possible, with a little patience, to procure a nest of the six sizes which will fit one inside the other. Judging from their symmetry I was prepared to learn when first making enquiries on this subject (1871) that these vessels, or at all events the larger sizes, were moulded with the aid of some rude form of potterswheel and certain statements made to me by the natives of the central group confirmed me in my erroneous surmise as to the existence in these islands of some such apparatus until I had an opportunity of observing the process for myself.

In answer to many enquiries I ascertained that the quality of

1 These jars are called shitōn and are extensively employed throughout the group chiefly for the purpose of catching rain-water as it falls from the under side of a slanting cocoanut tree; a spout is formed by an upward cut with adha, and the mouth of the jar, permanently kept immediately below, receives the flow on the fall of every passing shower. 
the clay used for the various sized pots is the same and that owing to the difficulty of drying the unbaked utensils during the rains, the manufacture of small pots only is attempted at that season of the year.

It was on the occasion of one of my official visits to Chowra that I was fortunate enough to have a chance of photographing and observing at close quarters the different stages of the manufacture, for it so happened that some women were busily engaged in shaping while others were firing previously prepared pots. ${ }^{1}$

Having prepared a quantity of clay by freeing it from small stones and other extraneous matter, and having kneaded it with fine sand until of a proper consistency, the operator seated herself on the ground and placed before her a piece of board on which she laid a ring or hoop (osiawa) about 8 inches in diameter made of cocoanut leaves neatly bound together, this served as a stand for a shallow dish (entana) in which was placed a circular piece of plantain leaf for the purpose of facilitating the manipulation of the clay by preventing its adhesion to the unglazed surface of the platter. With one or more handfuls of clay according to the size of the pot to be constructed, the base of the utensil was roughly shaped on the entâna, then rolls of clay of the required thickness and previously prepared were built up layer after layer until the proper dimensions had been attained. ${ }^{2}$ The operator the while turned the pot round and round, shaping it with her eye and hand; the result proved that long practice had made her quick to notice and correct any defect in her work in respect to symmetry of form whether through excess or deficiency in the thickness of the roll.

When the desired shape has been realized sufficiently to allow of the work being subsequently perfected the vessels are set aside on a raised platform to dry for one or two days according to the size of the pot and the state of the weather ; the tafal only,

\footnotetext{
1 When I witnessed the pot-making at Chowra, I was accompanied by two natives of the central group who, in spite of frequent visits to the island, had never before seen the process, it not being customary with these people, and especially with the inhabitants of that island, to gratify idle curiosity on the part of visitors and strangers, but to intimate, if necessary in plain terms, that their room will be preferred to their company, or in the case of Europeans to endeavour to mislead them or to attract their attention to some distant part of the island.

2 The variation amounting to an inch or more in the size of pots of the same class is due to the rule of thumb method which they employ for regulating the dimensions of these utensils : there being a wide range in the diameter of pots of the same form, no properly shaped pot between 9 inches and upwards of 20 inches across the mouth, would be reckoned too large or too small to be included under one or other of the varieties aforementioned.
} 
it seems, on account of its diminutive size, can be moulded and trimmed for the final firing in one day.

When a pot is deemed sufficiently dry for trimming and finishing it is taken from the platform and any superfluous clay in the interior is scraped off with a Cyrena shell, after which it is reversed and all excess of material externally is removed by means of a fine strip of bamboo (danun-kariang) which is frequently moistened with water-as are also the fingers of the potter-and gently passed over the inner and outer surfaces of the vessel in order to smooth them and give an appearance of finish to the work. The rim is also carefully made of as uniform a thickness as is possible with so rude an implement as the danun-kariang.

The pot is then replaced on the platform under the hut to harden for another 8 or 10 days before it is considered fit for the final process of firing. For this latter purpose a primitive kiln is prepared in some open space near the hut and bits of broken pottery are stuck in the ground a few inches apart, and in such a manner as to form a rough stand for the pot which is placed bottom upwards with the rim resting on the potsherds, and some 4 or 5 inches off the ground; in the space immediately under the pot a layer of fine wood ash and a quantity of cocoanut shells and scraps of firewood are heaped up and then a peculiar wheel-like object, called hiwat, of larger circumference than the pot, is laid on its up-turned base; against this are rested the branches and firewood which are to be lighted outside the vessel but which must not be allowed to come in actual contact with it, the length of these billets is of course regulated somewhat by the size of the utensil in course of firing.

When all these arrangements have been completed the fuel under and round the pot is kindled and the flame fanned if necessary by two or three women who, armed with sticks about 5 feet long in both hands, act as stokers, propping up and replacing the burning logs until the vessel is supposed to be sufficiently baked; it is then carefully removed by means of the above-mentioned sticks, and left to cool upon a bed of fine sand where, too, it receives the black stripes without which no Nicobarese pot is regarded as finished. This painting is a very simple process, being accomplished by means of strips of unripe cocoanut husk about 1 or 2 inches broad, which are laid on while the pot is yet hot; the stain produced by the acid juice contained in the husk turns black the moment it touches the heated surface, and a few seconds suffice to paint the requisite number of stripes down the sides and along the inner and outer edges of the rim; while so employed tiue ari sste keeps the pot in 
position by means of a cocoanut sheli cup, which she holds, edge outwards, in her left hand to save her fingers from being burnt. ${ }^{1}$

Finally, by way of giving a finish to the work, a handful of the moist strips of husk, wherewith the dark lines have been made, are passed over the entire outer and inner surfaces, witb the result that the acid not having been completely extracted, imparts a peculiar light copper colour to the parts not already stained with a deeper dye.

In order to identify pots it is a common custom to mark them before they are fired with some device peculiar to the maker, care being taken not to infringe upon the "rights" of others by adopting any sign likely to lead to confusion. These " trade marks," so to speak, may be observed either on the rim or on the outer surface of the pot, according to the space required for their portrayal; some sharp-edged tool, such as a dhá knife, or spear is used to make these designs. ${ }^{2}$

The aggregate number of pots made in the course of the year could hardly be ascertained with any degree of accuracy, but having regard to the small number of hands employed in the work-it must be very considerable; it appears that the largest demand is for the second and third sizes, and afterwards in order come Nos. 4, 5, 6, and 1 ; the smallest sizes tafâl are only sold in the neat little bundles usually containing five, which

1 These implements are made of different dimensions to suit the larger and smaller kinds of pots. The method of construction is as follows :-

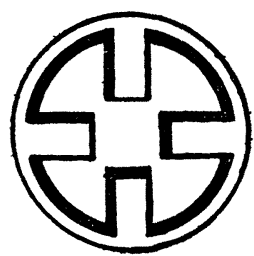

A circular lump of clay, similar to that used for the pots, is placed upon a plantain leaf, and on it is laid as a pattern another specimen, the outlines of which are sharply defined along the inner and outer edges with a knife, the model is then removed and a perfect duplicate is obtained, these objects are not baked, and are not considered ready for use under six months.

2 The following are examples of "trade-marks" recently observed on the rim of a pot :-

REDUCED SKETCH

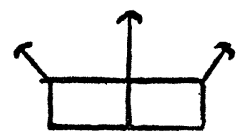

OF A DESIGN BELOW

OUTER LIP OF

ANOTHER POT.

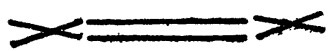


Journal of the Anthropological Institute, Vol. XXIII, Plate III.

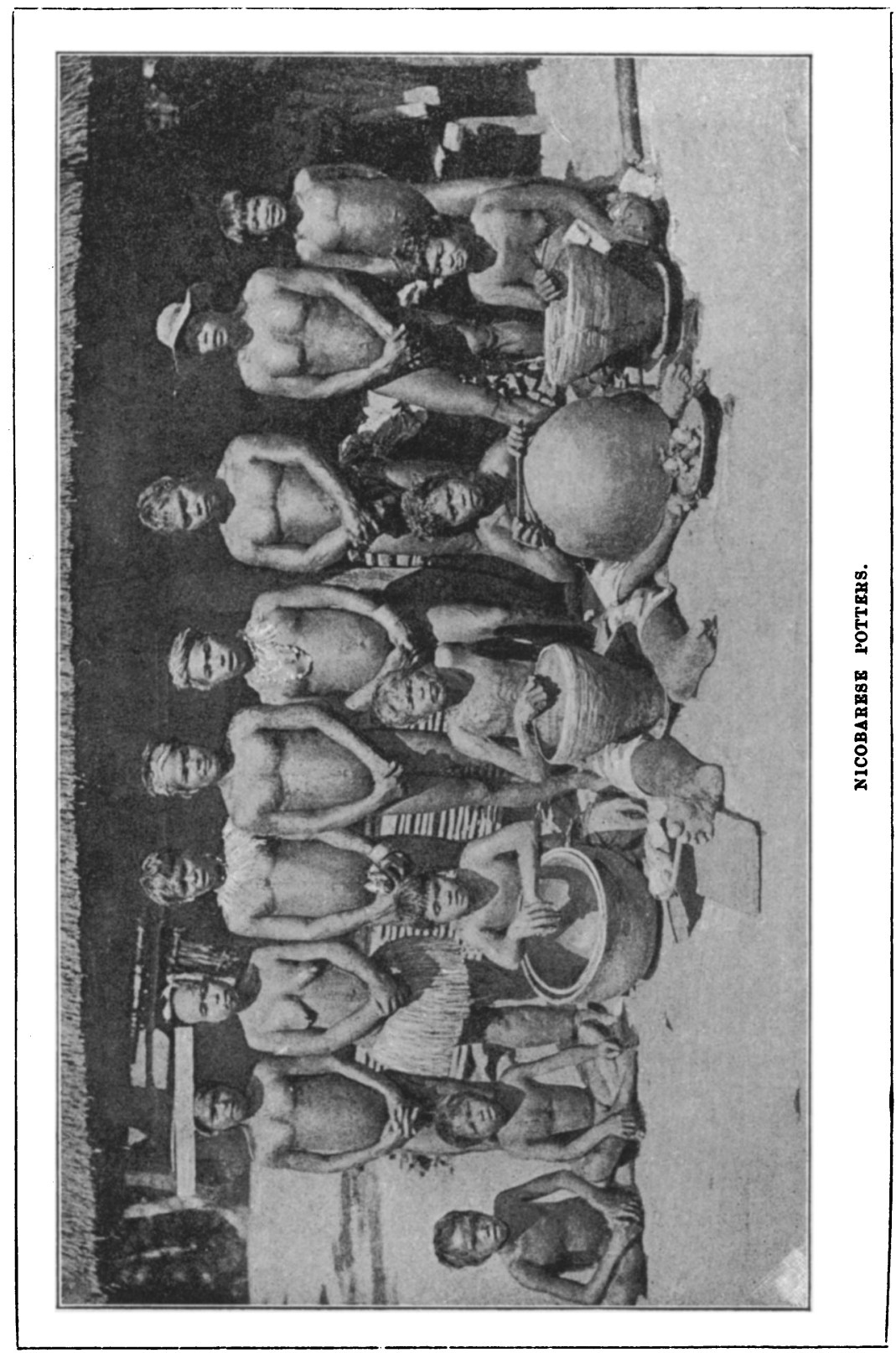


are called "kamintap," or "a set of five." Experience has taught the natives that to ensure the serviceableness of the pots for any length of time it is necessary to store them for a year or so in the heat and smoke of the huts; newly-made pots are therefore placed bottom uppermost on the lattice-work platform (lenp $\bar{a})$ with which huts at most of the islands are furnished in the space under the roof where the combined action of heat and smoke render the utensils hard and durable, so that they may be reckoned as good for a year's service, while freshly made pots, or those which have not been properly seasoned in the above manner, have been known to "fly" or become useless, if not at the first trial, at least within a brief period.

No earthen vessels are made specially for funeral purposes, but it is customary on the occasion of a death, for the relatives of the deceased to place on his or her grave, two of the largest pots as well as four smaller ones; they are there left for about six months, and then thrown away into the jungle, together with such other articles, e.g., spears, etc., as have been similarly deposited.

No porous pottery to serve for cooling drinks or any other kind of earthenware than that above described is manufactured, nor do the Nicobarese ever attempt to produce clay figures of men or animals.

\section{MaRCh 21st, 1893.}

Professor A. Macalister, M.D., F.R.S., President, in the Chair.

The Minutes of the last Meeting were read and signed.

The election of Charles James Longman, Esq., of 27, Norfolk Square, was announced.

The presents that had been received were announced, and thanks voted to the respective donors.

Dr. E. B. TrLor read a paper on "The Tasmanians as Representatives of Palæolithic Man."

Mr. J. A. Brown, Dr. J. G. GarsoN, and others took part in the discussion.

A paper by Professor Politis on "Burial Customs in Modern Greece" was read.

A paper by the Rev. J. Mathew on "The Cave paintings of Australia" was read. 